\title{
Columnar Ferrite Structure in Cast Iron Formed by Decarburization of White Cast Iron*
}

\author{
Fumitaka Otsubo ${ }^{1}$, Kousuke Matsuki $^{2}$, Hidenori Era $^{3}$ and Hidenori Kuroki ${ }^{4}$ \\ ${ }^{1}$ Center for Instrumental Analysis, Kyushu Institute of Technology, Kitakyushu 804-8550, Japan \\ ${ }^{2}$ Graduate School of Engineering, Kyushu Institute of Technology, Kitakyushu 804-8550, Japan \\ ${ }^{3}$ Faculty of Engineering, Kyushu Institute of Technology, Kitakyushu 804-8550, Japan \\ ${ }^{4}$ Hiroshima University, Higashi-hiroshima 739-0046, Japan
}

Cast iron objects such as axes and other artifacts excavated from ancient sites generally have a layered structure with columnar ferrite on the outside, changing to pearlite and ledeburite with increasing depth, together with a minor fraction of dispersed graphite; this structure is the result of the heat treatment used in the decarburization process. The formation of the columnar ferrite structure has previously been explained by assuming that cast iron was produced using a metal mold and then decarburized.

In this study, in order to clarify this issue, decarburization experiments were performed on white cast iron. Part of a white cast iron block, containing the surface that had been in contact with the mold during casting, in addition to a cut surface, was heated to $1273 \mathrm{~K}$, held at that temperature for $96 \mathrm{~h}$, and then slowly cooled to $873 \mathrm{~K}$ at $67 \mathrm{~K} / \mathrm{h}$ (for $6 \mathrm{~h}$ ). It was found that columnar ferrite crystals grew in the direction perpendicular to the surface regardless of the solidification direction. The ferrite structure did not have a uniform crystal orientation, similar to the case for partially decarburized ancient cast iron. Therefore, this clarified that the issue was a misunderstanding without materials scientific grounds. In addition, when white cast iron was decarburized at $1123 \mathrm{~K}$ for $48 \mathrm{~h}$ and cooled to $873 \mathrm{~K}$ at $42 \mathrm{~K} / \mathrm{h}$, the overall thickness of the decarburized layers was close to that for ancient artifacts. Therefore, it is likely that in ancient times, the same type of cast iron and heat treatment conditions were used. [doi:10.2320/matertrans.F-M2018822]

(Received February 26, 2018; Accepted May 11, 2018; Published July 25, 2018)

Keywords: columnar ferrite, decarburization, ancient cast iron, white heart malleable, white cast iron, pure iron

\section{Introduction}

\subsection{Background of study}

Much ironware produced by casting is found from remains of the Yayoi period in Japan. The cross-sectional structure of surface of an iron axe-head excavated from such remains revealed a white malleable cast iron structure with decarburization and columnar ferrite present on the decarburized surface (Fig. 1). ${ }^{1)}$ The compositional characteristics of the cast iron were similar to a columnar ferrite structure common in those days and generally of high purity due to an extremely low silicon content $(0.08$ mass $\%) .{ }^{2)}$ The content of manganese and sulfur is also low. It is considered that the appearance of columnar ferrite indicates a transformation structure with decarburization. ${ }^{3,4)}$ However, some steel researchers have argued that the appearance of columnar ferrite is the result of crystal growth by rapid cooling; ${ }^{5)}$ there is also a claim that it could be due to the rapid cooling by metal mold casting. ${ }^{\text {) }}$

The aim of this study was to obtain a materials science explanation regarding the formation process of this type of columnar ferrite structure by analysis of the decarburized structure. The relationship between crystal growth direction during casting and the change in structure that accompanies the decarburization process during the annealing of low silicon white malleable cast iron was investigated. In addition, a cast iron piece excavated from the remains of Umenoki of Kikuyo-town, Kumamoto Prefecture ${ }^{7)}$ (Sign UMK-15; lent by the Kumamoto Prefectural Board of Education) was selected as a representative sample of ancient ironware. An attempt was made to determine the heat-

*This Paper was Originally Published in Japanese in J. JFS 90 (2018) 6167.

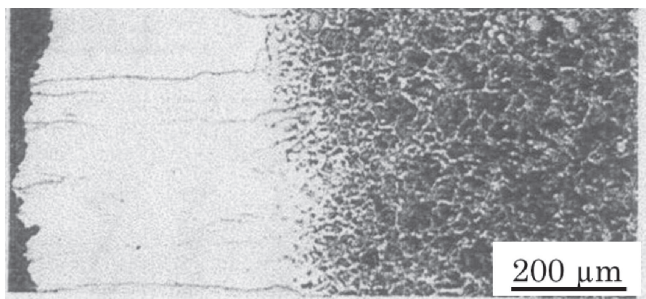

Fig. 1 Cross-sectional microstructure of ancient cast axe-head.

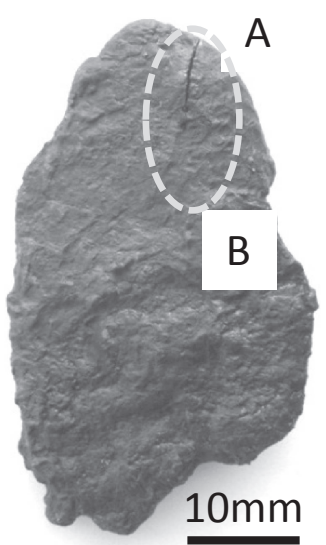

Fig. 2 Appearance of rusted mass of ancient cast iron "UMK-15".

treatment conditions used to produce ancient ironware by observation of the detailed characteristics of the columnar ferrite structure in an $\mathrm{AB}$ domain of the piece, as shown in Fig. 2. Furthermore, the growth direction of the columnar ferrite structure was investigated using the electron backscatter diffraction (EBSD) method for ancient and modern decarburized cast iron. 
(a)

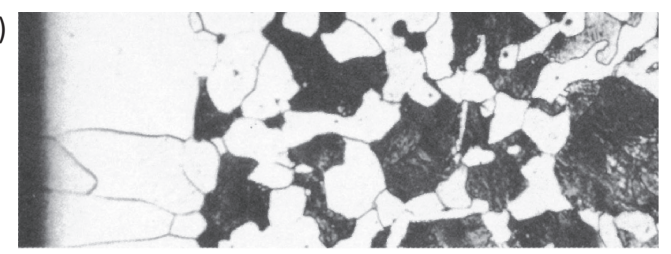

(b)

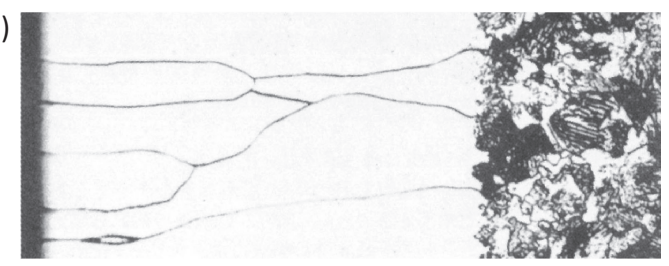

Fig. 3 Columnar ferrite layer formed in 1.0 mass $\% \mathrm{C}$ steel by decarburization in moist hydrogen atmosphere. ${ }^{3)}$ (a) heated at $1198 \mathrm{~K}$ for $4 \mathrm{~h}$. (b) heated at $1073 \mathrm{~K}$ for $6 \mathrm{~h}$.

\subsection{Characteristics of columnar ferrite structure formed by decarburization}

The columnar ferrite structure is similar to the recrystallization structure of extremely mild rolled steel sheet (texture of the preferred crystallographic orientation). It is also similar to the metal mold casting structures of pure aluminum in that the crystals of the single phase grow towards the inside and perpendicularly from the surface. It is common that the growth direction of ledeburite as the matrix of white cast iron is approximately perpendicular to the cooling surface. ${ }^{8)}$ The columnar ferrite structure even occurs in the general decarburization of rolled carbon steel materials, which has been published in a collection of steel structure photographs $^{9,10)}$ (e.g., Fig. 3 in Ref. 10)). The columnar ferrite structure also forms in industrial pure iron by decarburization. The same structure has also been reported to form in super high-purity iron. ${ }^{11)}$

\section{Experimental Procedure}

High-purity pig iron containing 3.8 mass $\%$ carbon was used in this study, the chemical composition of which is shown in Table 1. The specimen in a graphite crucible was melted by blowing argon gas from the upper part of the crucible in an induction furnace. The iron ingot was heated to $1673 \mathrm{~K}$ to melt them. After completely melting, the molten metal was poured into a mold made of cast iron at $1533 \mathrm{~K}$. Mainly wedge-shaped ingots were made, but also some plate-type samples. Figure 4 shows schematic drawings of a wedge-shaped ingot and a cut specimen with dimensions and the observation plane.

Decarburization occurs equally from the surface of castings when castings are placed in a decarburization atmosphere. On the other hand, when a part of the casting is cut off, the cut surface represents a new surface. Decarburization then occurs over all of the casting surface and the cut surface. Ferrite grows towards the inside of castings over time (with a drop in temperature), and then the growth of columnar ferrite occurs gradually at the surface of the casting (ingot) with sufficient decarburization treatment after cooling to soften the casting.

Solidification and decarburization occur together in the $\mathrm{x}$-axis direction in an area solidified close to the mold, as

Table 1 Chemical composition of specimen (mass\%).

\begin{tabular}{cccccc}
\hline $\mathrm{C}$ & $\mathrm{Si}$ & $\mathrm{Mn}$ & $\mathrm{P}$ & $\mathrm{S}$ & $\mathrm{Fe}$ \\
\hline 3.8 & 0.02 & 0.02 & 0.05 & $\leqq 0.01$ & bal. \\
\hline
\end{tabular}

(a)

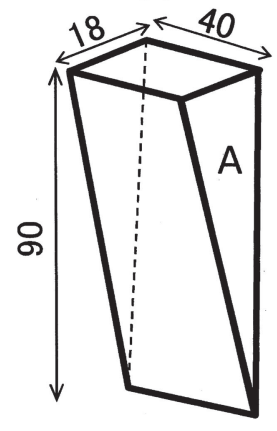

Fig. 4 Schematic dimension of wedge-shaped ingot. (a) as-cast, decarburization, (c) microstructure observation.

denoted by $\mathrm{A}$ in Fig. 4. This is a solidification and decarburization parallelism type structure by decarburization of the solidification surface. The solidification direction is almost along the $y$-axis in the cut area $\mathrm{B}$, whereas decarburization occurs in the direction of the $\mathrm{x}$-axis, at right angles to area $\mathrm{B}$ formed on the face by cutting. The relationship of the solidification structure and decarburization can be examined by comparing the structure formed in the decarburization directions that are the same as the solidification direction, and in the decarburization directions different from the solidification direction. In this study, this is referred to as a decarburization experiment after cutting one end of a sample.

A small electric desk-furnace was used for the decarburization experiment after cutting one end of an ingot. A cut specimen is placed in a decarburization container with a granular decarburization agent and heat-treated because a ferrite layer that is sufficiently thick is required for white malleable cast iron after the treatment. The container was a steel can with a cover and dimensions of $145 \mathrm{~mm}$ wide, $105 \mathrm{~mm}$ deep and $45 \mathrm{~mm}$ high. The decarburization agent was composed of approximately 75 mass $\% \quad \mathrm{Fe}_{2} \mathrm{O}_{3}$, and several percent of calcia, alumina, and silica, respectively. The specimen was annealed at $1273 \mathrm{~K}$ for $24 \mathrm{~h}$, cooled off at $67 \mathrm{~K} / \mathrm{h}(6 \mathrm{~h})$ to $873 \mathrm{~K}$, and then held for $96 \mathrm{~h}$ before air cooling to room temperature, by which the decarburized structure was obtained. The annealing condition referred to as a standard condition was 1223 to $1323 \mathrm{~K}$ for 40 to $70 \mathrm{~h}^{12}$ )

A cut plate-type specimen $(10 \mathrm{~mm}$ wide, $7 \mathrm{~mm}$ deep and $25 \mathrm{~mm}$ high) was placed in a steel can (62 mm wide, $45 \mathrm{~mm}$ deep and $62 \mathrm{~mm}$ high) to reproduce the decarburization conditions of the ancient cast iron. The decarburization conditions were changed with consideration of the resultant ferrite layer and carbon steel layer observed, which were thinner than those for the wedge-shaped specimen. The decarburization agent was added at 4 times the mass ratio of pure iron powder to suppress the decarburization effect. The conditions that were changed to restrain the decarburization effect were temperature and annealing time; the specimen 
Table 2 Conditions of annealing.

\begin{tabular}{|c|c|c|c|c|}
\hline Sample & $\begin{array}{c}\text { Heating } \\
(\mathrm{hr})\end{array}$ & $\begin{array}{c}\text { Temp. } \\
\text { (K) }\end{array}$ & $\begin{array}{c}\text { Holding } \\
(\mathrm{hr})\end{array}$ & $\begin{array}{l}\text { Cooling } \\
\text { (K/hr) }\end{array}$ \\
\hline Wedge & 24 & 1273 & 96 & 67 \\
\hline \multirow{7}{*}{ Flat } & \multirow{7}{*}{1} & \multirow{4}{*}{1273} & \multirow{4}{*}{24} & 42 \\
\hline & & & & Water cooling \\
\hline & & & & 67 \\
\hline & & & & Water cooling \\
\hline & & \multirow{3}{*}{1123} & 12 & \multirow{3}{*}{42} \\
\hline & & & 36 & \\
\hline & & & 48 & \\
\hline
\end{tabular}

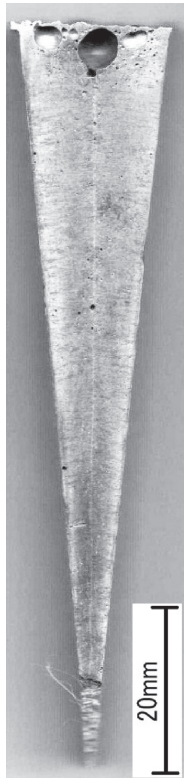

Fig. 5 Macro cross-section of as-cast wedge-shaped ingot (plane B in Fig. 4(b)).

was heated to $1273 \mathrm{~K}$ or $1123 \mathrm{~K}$ as lower temperatures over a $1 \mathrm{~h}$ period, held for 12 to $24 \mathrm{~h}$, and then cooled or water cooled to $873 \mathrm{~K}$ over a $6 \mathrm{~h}$ period. The annealing conditions are shown in Table 2.

Both the wedge-shaped and plate-type specimens were wet-polished and etched with $10 \%$ Nital solution after heattreatment to observe the decarburization depth. Structural observation was conducted using optical microscopy. The plate-type specimen was also analyzed using scanning electron microscopy (SEM) and EBSD to investigate the crystal orientation of the columnar ferrite.

\section{Experimental Results}

\subsection{Casting structure}

As shown in Fig. 5, the columnar structure grows from the solidification surface to form an end face and two slopes that face each other toward the center of the wedge specimen before the decarburization treatment. On the other hand, such an equiaxed crystal area, which are usually observed in the center of many ingots produced by metal molding, was not observed. A ledeburite microstructure was observed over the entire surface when observing the columnar-like macrostructure, as shown in Fig. 6.

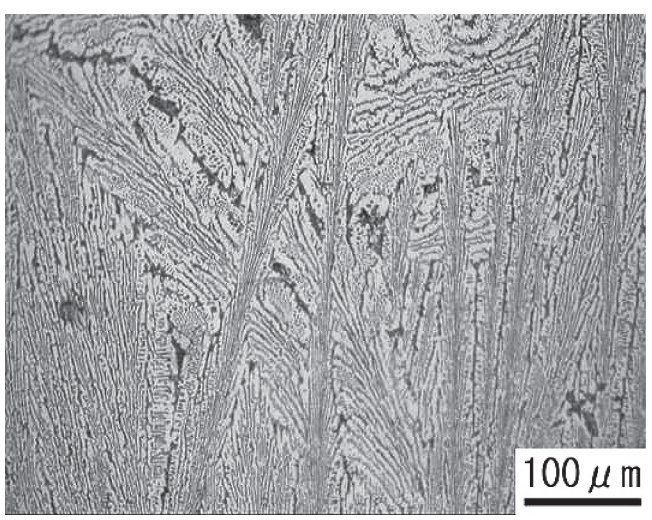

Fig. 6 Microstructure as-cast wedge-shaped specimen in Fig. 5.

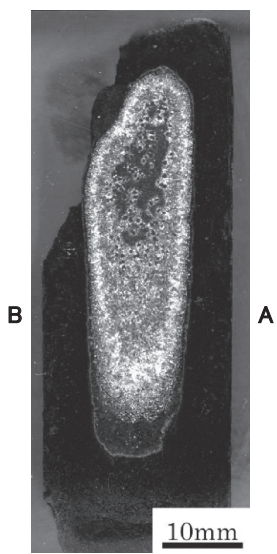

Fig. 7 Macro cross-section of wedge-shaped specimen after decarburization (plane C in Fig. 4(c)).

\subsection{Structure in the decarburization experiment after cutting one end}

\subsubsection{Macrostructure}

The wedge-shape white cast iron specimen was held at $1273 \mathrm{~K}$ for $96 \mathrm{~h}$ for the decarburization process and was slow-cooled to $873 \mathrm{~K}$ at $67 \mathrm{~K} / \mathrm{h}$ and then cooled to room temperature in the furnace. The cross-sectional macrostructure of specimen is shown in Fig. 7. The change in the macrostructure from each surface to the inside was similar to the solidification side (right) and the cut surface side (left) in Fig. 7. However, an approximately $5 \mathrm{~mm}$ thick oxide layer on one side was adhered on the specimen surface after decarburization. The width of the metal area decreased from the original $18 \mathrm{~mm}$ to approximately $12 \mathrm{~mm}$, which suggests that significant oxidation occurred during decarburization.

\subsubsection{Ledeburite and columnar ferrite}

To compare the decarburized structure with a casting structure, the ingot was cut so that the surface was divided at the vertical angle of the sharp wedge into two. A crosssectional micrograph (Fig. 8(a)) and magnified micrographs of the columnar ferrite area that appeared white at both ends (Figs. 8(b) and (c)) are shown in Fig. 8. The right-side end (b) is the end face (A face in Fig. 4) of the wedge and ledeburite began to grow in the $\mathrm{x}$-axis direction (width direction of the wedge) towards the left side from the right side. The other left edge (c) is an acute triangle to divide the 


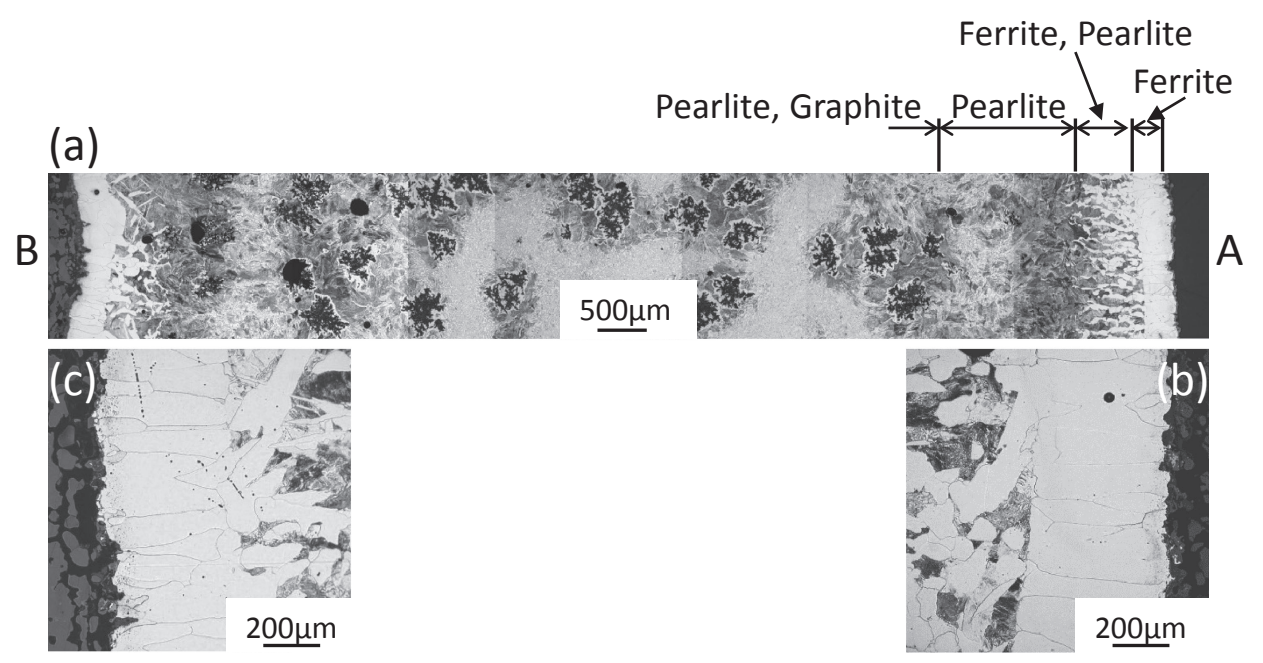

Fig. 8 Microstructure of decarburized wedge-shaped specimen in Fig. 7. Wide photo through cut side to solidified side (a), solidified side (b) and cut side (c) magnified photos from (a), respectively.

width of the wedge into two, parallel to the end face of the wedge. In other words, the side is cut down the hatched side of B in Fig. 4. Therefore, the micrograph in Fig. 8(c) shows the new cut face. In addition, the cut end part shows ledeburite column growth at almost right angles from the side slope of the wedge (Fig. 8(c)).

The formation of columnar ferrite crystals can be confirmed from just inside the oxidation layer, which is the decarburized surface growing toward the inside from both mold wall (the solidification surface) sides and the cut surface side in Figs. 8(a) through (c). A ferrite/pearlite hypoeutectoid mixture is present in the bulk and the structure is joined to a eutectoid of pearlite. Although this change is common with a decarburized structure of rolled carbon steel, a eutectoid of pearlite and cotton-like graphite is present within the pearlite, and growth of a structure composed of pearlite and cementite continues, while the white cast iron layer left in the center is non-decarburized (granulation of the structure begins). Overall, the quantity of carbon increases continually toward the inside because decarburization advances from the surface to the inside.

The directionality of both structures of the ferrite formed after treatment and ledeburite in the surface layer of white cast iron before the decarburization experiment and after cutting one end of the sample was compared. According to the high magnification images of the surface layers in Figs. 8(b) and (c), which correspond to areas A and B in Fig. 4, the columnar ferrite structure is formed along the direction (horizontal direction) of the decarburization process in both areas. In Fig. 8(b) of the mold wall (solidification surface) side, the growth direction of ledeburite in the matrix before decarburization is in agreement with the growth direction of the ferrite formed after decarburization.

On the other hand, the ferrite growth by decarburization is not affected by the growth direction of ledeburite, because growth of the columnar ferrite structure is horizontal in the area where the ledeburite structure is perpendicular to the observation surface (micrograph plane) in Fig. 8(c) of the cut surface side.

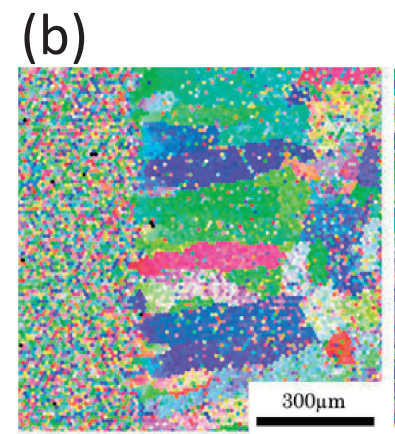

(a)

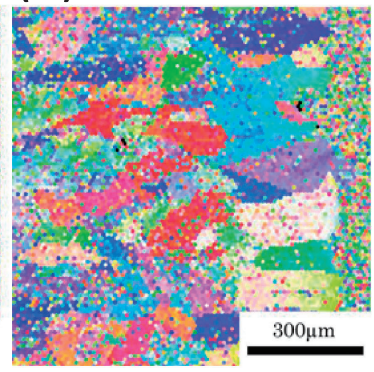

111

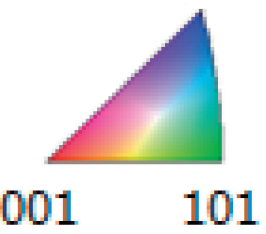

Fig. 9 IPF map of columnar ferrite layer in wedge-shaped specimen. Solidified side (a) and cut side (b).

\subsection{Crystallographic orientation analysis of columnar ferrite related to transformation}

EBSD analysis was performed to determine the crystallographic orientation of the columnar ferrite crystal in the ingot from the decarburization experiment after cutting one end. Figures 9(a) and (b) show the texture not to have an equivalent growth direction due to the random crystallographic orientation of the columnar ferrite crystal determined by EBSD analysis. The texture of the columnar ferrite structure (Fig. 10) is similar to a piece of ancient decarburized cast iron remains excavated at Umenoki, Kumamoto prefecture. ${ }^{7)}$

\subsection{Formation of columnar ferrite structure by decarburization of plate-type white cast iron}

As discussed in section 3.2, the treatment conditions were changed due to the significant oxidation recognized in the 

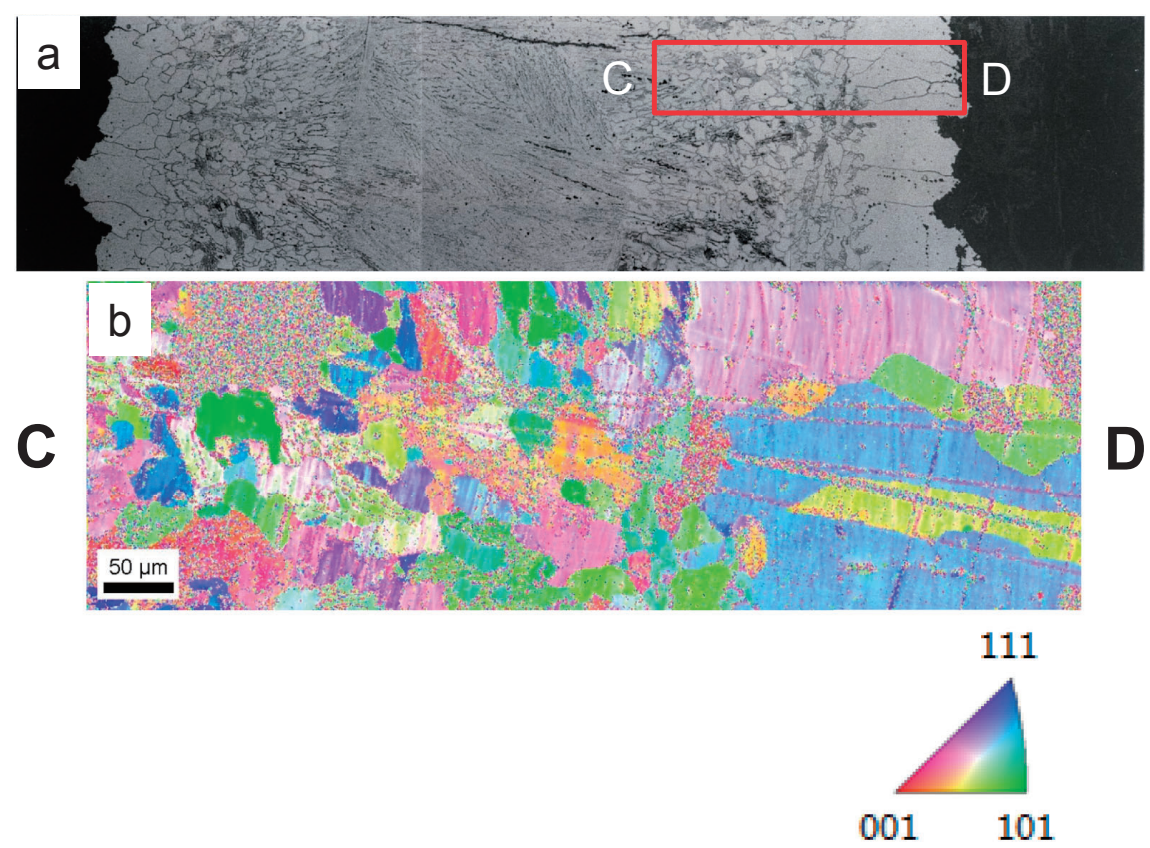

Fig. 10 Microstructure (a) and IPF map (b) of columnar ferrite in cross-section of ancient decarburized cast iron "UMK-15".
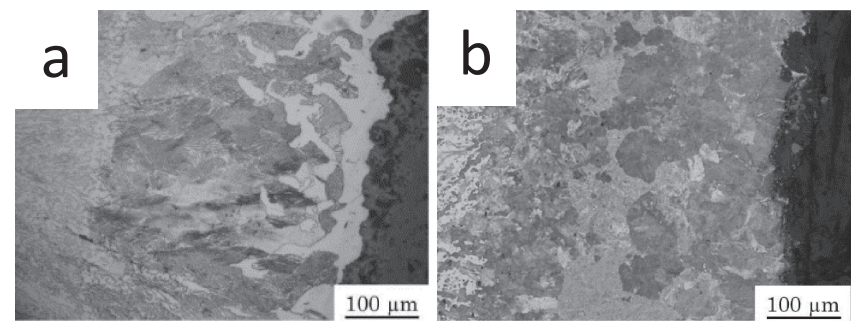

Fig. 11 Microstructure of specimen after decarburization at $1123 \mathrm{~K}$ for 24h. (a) slow-cooled (b) rapid-cooled.

wedge-shaped cast iron after the decarburization experiment and cutting one end.

The plate-type white cast iron was placed in the steel can with the decarburization agent. One specimen was heated at $1123 \mathrm{~K}$ to achieve an equivalent ferrite level of pure iron treated for $1 \mathrm{~h}$. After holding at $1123 \mathrm{~K}$ for $24 \mathrm{~h}$, the specimen (slow cooled specimen) was cooled in the furnace to $873 \mathrm{~K}$ at $42 \mathrm{~K} / \mathrm{h}$ and subsequently cooled in air.

The other specimen (rapid cooled specimen) was heated at a decarburization temperature of $1123 \mathrm{~K}$. After holding at $1123 \mathrm{~K}$ for $24 \mathrm{~h}$, the specimen was cooled in water. However, it may be considered that the change in temperature on the specimen surface with a granular decarburization agent passes the transformation temperature level within several seconds, or the cooling rate become almost the same as that for a specimen corresponding to cooled in oil or air. The structures of the slow cooled and rapid cooled specimens are shown in Figs. 11(a) and (b), respectively. A layer of single-phase ferrite can be confirmed on the surface of the slow cooled specimen in Fig. 11(a). However, the columnar crystals observed in the wedge-shaped specimen were not observed and hypoeutectoid steel with troostite and pearlite, and a structure equivalent to eutectic steel in the bulk was evident. The non-decarburized layer is present from the surface inward to a boundary located approximately $0.4 \mathrm{~mm}$

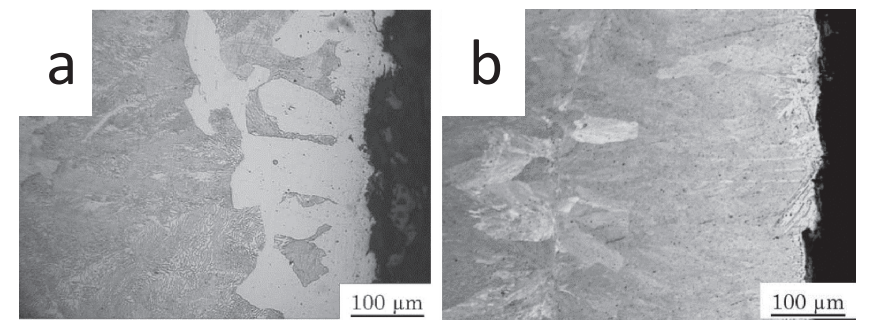

Fig. 12 Microstructure of specimen after decarburization at $1273 \mathrm{~K}$ for $24 \mathrm{~h}$. (a) slow-cooled (b) rapid-cooled.

from the surface. On the other hand, the ferrite structure was not observed in the water cooled specimen etched with Nital, as shown in Fig. 11(b). There is a first dark layer over most of the surface. The thin white layer inside of the first layer may be ferrite precipitated at the grain boundaries. It is considered that the second layer mixed in slightly with bright gray and dark gray areas inside of the first layer is martensite. In addition to the interior is a pearlite structure with clear lamella form and a structure reaching the hypereutectoid steel through eutectoid steel from hypoeutectoid steel. The structure is connected to the ledeburite-like non-decarburized layer at approximately $0.4 \mathrm{~mm}$ from the surface, similar to the slow cooled specimen.

Next, the structure of specimens slow cooled at $67 \mathrm{~K} / \mathrm{h}$ and water cooled after holding for $24 \mathrm{~h}$ at $1273 \mathrm{~K}$ (heating to temperature over $1 \mathrm{~h}$ ) are shown in Figs. 12(a) and (b), respectively. In this case, the change is shown to be similar to the specimen heated at $1123 \mathrm{~K}$, which is free from columnar ferrite structures. A layer of single-phase ferrite was observed on the surface of the slow cooled specimen (a). Ferrite appeared as Widmanstätten-like needles in the water cooled specimen (b) and no columnar crystals appeared in any of the specimens. Ledeburite appeared approximately $1.6 \mathrm{~mm}$ from the surface in the specimen held at $1273 \mathrm{~K}$ for $24 \mathrm{~h}$, for either cooling rates. 
No columnar ferrite structures were formed in either of the specimens by lowering the treatment temperature and shortening the time to suppress the decarburization effect, or in the rapidly cooled specimen to inhibit the growth of ferrite nuclei after decarburization. Thus, strong decarburization and slow cooling result in formation of the columnar ferrite structure.

\section{Discussion}

\subsection{Direction relationship of ledeburite formed earlier and ferrite formed later by decarburization}

Figure 13 shows schematic images of the change in macrostructure with respect to the ledeburite and columnar ferrite structures obtained through the decarburization experiment. The form of the figure is xy horizontal projection to show the cut wedge-shaped specimen at a height with the middle of the $\mathrm{z}$ direction in Fig. 4. Figure 13(a) shows a cross-sectional macrostructure of the ingot at the time of casting. Ledeburite growth occurs from the surface of the ingot towards the inside. The macrostructure after cutting $(\mathrm{z}$ direction) the upper half of the ingot is shown in Fig. 13(b). When decarburizing this ingot, columnar ferrite crystals develop from all surfaces exposed to the decarburization atmosphere, as shown in Fig. 13(c).

Both structures of ledeburite and ferrite exhibit a columnar growth mechanism, where growth occurs from a small nucleus at the starting point and extends inside to form both columnar crystals. The starting point of ledeburite is the surface of the ingot. The starting point of ferrite is also the surface of the ingot (including the cutting surface), i.e., the surface exposed to decarburization and the cooling environment (atmosphere). The cross-section of Fig. 13(d) shows the growth of ledeburite and ferrite structures in the same direction because both structures are in agreement with respect to the starting points of decarburization, which is the cooled casting surface (A part) as shown in Fig. 8. On the other hand, both structures may not be necessarily parallel in the cutting surface side of the decarburized and cooled ingot. Decarburization and the cooling direction rules the direction of the ferrite structure, regardless of the ledeburite direction. When the column of ledeburite grows in the form shown in Fig. 13(b), towards the inside from the slope of the cut wedge-shaped ingot, cooling typically occurs from the newly (a)

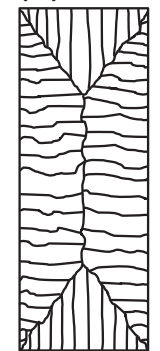

(b)

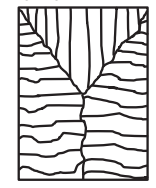

(c) $\mathrm{A}$

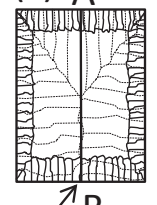

(d)
Fig. 13 Schematic change in macrostructure through casting and decarburizing. (a) ledeburite in as-cast wedge-shaped ingot. (b) upper half of bisected ingot (a) before decarburization. (c) ferrite layer from surface of (b) after decarburization. (d) vertical cross-section of decarburized ingot for Fig. 8. cut surface towards the inside, as shown by part B in Fig. 13(c), and the growth of the ferrite structure becomes cross-sectional for the ingot structure. Therefore, the growth of columnar ferrite does not inherit the direction of ledeburite from the surface in the cut surface side towards the inside after decarburization, although ferrite seems to form with the columnar growth of ledeburite at the ingot surface side. When the ingot is decarburized after cutting, the columnar ferrite structure with the same morphology appears, regardless of the ingot surface side and the cutting surface side.

When considering the change in the structure by strong decarburization in white cast iron at the temperature higher than the $\mathrm{A}_{3}$ transformation temperature of iron, the surface layer transforms from a single-phase of low-carbon austenite because carbon is oxidized and eliminated at the surface and a slope of carbon concentration occurs in the austenite layer with the surface concentration decreased. It is supposed that a single-phase ferrite layer forms due to generation a nucleus of ferrite crystal on the surface and then growth of columnar crystals on the inside with cooling progress, when the cooling process begins, in addition the effect of occurring the difference in temperature between the decarburized surface and the inside.

Next, we consider the process of the decarburization of white cast iron in the two phase ferrite/austenite temperature range of the equilibrium phase diagram of iron-carbon $\left(\mathrm{Fe}_{3} \mathrm{C}\right)$ (between the eutectoid point $1000 \mathrm{~K}=727^{\circ} \mathrm{C}$ and $\mathrm{A}_{3}$ point $1185 \mathrm{~K}=912^{\circ} \mathrm{C}$ ). In this case, a ferrite nucleus forms on the surface at the decarburization temperature and grows towards the inside. Furthermore, it is supposed that significant growth of the columnar structure also occurred due to the additional effect of the difference in temperature between the surface and the inside through the cooling process.

Regardless of the decarburized temperature, the columnar ferrite forms along with decarburization and subsequently the same direction as ledeburite growth by slow cooling without the influence of the solidification direction that ledeburite shows. Therefore, the argument ${ }^{6)}$ that white cast iron was cast by metal molding due to the formation of columnar ferrite crystal in the surface layer of ancient white cast iron by decarburization does not hold because the growth direction is independent of the ledeburite growth direction. There are no materials science grounds for this argument, and its failure was thus clarified.

\subsection{Crystallographic orientation of columnar ferrite along temperature gradient}

EBSD analysis was performed for various columnar ferrite structures. The growth direction of each columnar crystal was different from other columnar crystals. The aligned texture was not confirmed; therefore, it was reconfirmed that the structure newly formed by decarburization treatment in conjunction with the columnar ferrite crystal growth is formed regardless of the growth direction of ledeburite.

On the other hand, the ferrite easily forms a columnar structure $^{11)}$ in industrial pure iron with extra low carbon led to a strongly decarburized level of $20 \mathrm{ppm} \mathrm{C}$, such as the surface layer of white malleable cast iron when $\mathrm{Ar}_{3}$ transformation occurs under a temperature gradient (cooling 
in the furnace and one end cooling correspond). However, the columnar crystals that appear in the extra low carbon iron do not have the aligned texture observed in mild steel sheet. This is because individual crystals grow in the same direction, as confirmed by optical microscopy observations.

Therefore, the columnar ferrite structure that forms along the temperature gradient from the specimen surface to the inside during the $\mathrm{Ar}_{3}$ transformation is considered to easily coarsen because the transformation progresses slowly. It is noted that orientation does not act on this occasion, because the structure formation process is slow, so that the texture formed does not have a specific crystallographic orientation.

\subsection{Time of columnar ferrite structure formation in decarburized cast iron}

Whereas the thick columnar ferrite formed in the slow cooled specimen after decarburization for $96 \mathrm{~h}$ at $1273 \mathrm{~K}$, which corresponds to the austenitic state of iron, the columnar crystals are not formed though the ferrite layer occurs at the specimen surface by slow cooling after decarburization for $24 \mathrm{~h}$ at $1123 \mathrm{~K}$, which corresponds to the ferritic state, and as with that at $1273 \mathrm{~K}$. A martensite layer is also formed at the specimen surface when the sample is water cooled after decarburization for $24 \mathrm{~h}$ at $1123 \mathrm{~K}$. If the decarburization time is $24 \mathrm{~h}$, then the columnar ferrite crystals do not form under either the decarburization or the cooling conditions; therefore, the columnar ferrite structure was not formed by the mechanism common to rapid solidification of a casting. It is thus considered that the main contribution to formation of the columnar ferrite structure is the length of the decarburization time and slow cooling after decarburization in one direction.

Pay attention to that matter, decarburization was then performed near $1123 \mathrm{~K}$, based on an assumption of the Umenoki specimen. The decarburization treatment for the reproduction experiment was changed 12 through $48 \mathrm{~h}$ and thickness of the carbon steel layer then became approximately $500 \mu \mathrm{m}$, which was close to that of the Umenoki specimen for treatment over 36 and $48 \mathrm{~h}$. Therefore, it is considered that a similar treatment was applied to achieve reproduction close to the Umenoki specimen due to formation of the $500 \mu \mathrm{m}$ thick carbon steel layer. Accordingly, the appearance of a columnar ferrite layer could be identified as one possibility that the same processing was applied for the decarburization treatment. However, the thickness of the ferrite in the outermost layer cannot be directly compared because the outermost layer could be easily affected by corrosion of remains underground over time.

\section{Conclusions}

(1) The specimen was prepared by cutting white cast iron made from pig iron through casting. Columnar ferrite crystal was confirmed to form, regardless of the ledeburite growth direction in the specimen surface of a decarburized specimen after cutting one end held at $1273 \mathrm{~K}$ for $96 \mathrm{~h}$ to decarburize followed by slow cooling to $873 \mathrm{~K}$.
(2) Columnar ferrite crystals formed by the decarburization of cast iron did not have crystallographic orientation such as the columnar structure formed by recrystallization. Similarly, the columnar ferrite structure of the ironware surface from the remains of Umenoki did not have crystallographic orientation.

(3) As a first step of the experiment to reproduce the characteristics of the ironware remains of Umenoki, it was supposed that the ironware was given a decarburization treatment under conditions determined from a decarburization experiment of white cast iron held at $1273 \mathrm{~K}$ for $48 \mathrm{~h}$ and cooled at a rate of $42 \mathrm{~K} / \mathrm{h}$. The total thickness of the hypoeutectoid and eutectoid layers, was close to that of the Umenoki ironware, except the thickness of the ferrite layer, which may be due to the effect of corrosion, whereby the ferrite layer on the remains is easily removed.

(4) In contrast to the idea that a metal mold causes rapid solidification in casting and subsequent appearance of the columnar ferrite structure, the extra low-carbon ferrite layer was formed by decarburization, regardless of the growth direction of the solidification structure, and the slow columnar growth of the ferrite crystal occurred in the extra low carbon pig iron layer after decarburization.

\section{Acknowledgment}

The cast iron specimen of the remains of Umenoki was borrowed by Manabu Kameda from the Kumamoto Prefectural Board of Education. The authors thank Manabu Kameda, Masami Osawa and Mizuho Suzuki of Kyushu Techno Research Company for specimen preparation. The authors also acknowledge the Center for Instrumental Analysis, Kyushu Institute of Technology for conducting the EBSD analysis.

\section{REFERENCES}

1) M. Osawa: Hie-iseki Gun(Hie-remains) 21 -Report of the 51st Investigation-, (Fukuoka-city Education Board, 1996) pp. 47-58.

2) Y. Jun: WW 2 (1975) 19-25.

3) T. Owadano: Proc. of the Symposium in the 150th Meeting of the Iron and Steel Inst. of Japan (2005) pp. 37-46.

4) T. Owadano: J. JFS 78 (2005) 470-477.

5) M. Osawa: Proc. of the Symposium in 164th Meeting of the Iron and Steel Inst. of Japan (2012) pp. 40-58.

6) M. Osawa: Early Stage Ironware of the Yayoi Period 〈Malleable cast iron products $>$ - Approach Through a Metallurgical Investigation -, (Papers on iron making history, Tatara-kenkyukai, Hiroshima, 2000) pp. 513-552.

7) M. Osawa and M. Suzuki: Metallurgical Analysis of the Iron Products, (The remains of Umenoki II volume, 1st Search report on the cultural properties of Kumamoto prefecture 199th, Kumamoto Prefecture Education Board, 2001) pp. 55-73

8) T. Usami and Y. Serita: J. JFS 43 (1971) 463-469.

9) T. Sato: Micrographs and Commentary on Iron and Steel, (3th enlarged edition, Maruzen, Tokyo, 1985) pp. 70-71.

10) T. Nishizawa and T. Sakuma: Collection of Metal Structure Photographs Iron and Steel Materials, (Maruzen, Tokyo, 1979) p. 71.

11) K. Abiko: Materia Japan 52 (2013) 259-265.

12) N. Tsutsumi and O. Madono: Malleable Cast Iron, (Tonami publisher, Tokyo, 1964) p. 186. 